\title{
Plasminogen activator inhibitor- $I$ is elevated in patients with COPD independent of metabolic and cardiovascular function
}

This article was published in the following Dove Press journal:

International Journal of COPD

22 March 2017

Number of times this article has been viewed

\author{
Benjamin Waschki ${ }^{1-3}$ \\ Henrik Watz ${ }^{2,3}$ \\ Olaf Holz $\mathrm{z}^{4,5}$ \\ Helgo Magnussen ${ }^{2,3}$ \\ Beata Olejnicka ${ }^{6}$ \\ Tobias Welte ${ }^{5,7}$ \\ Klaus F Rabe ${ }^{1,3}$ \\ Sabina Janciauskiene ${ }^{5,7}$ \\ 'Pneumology, LungenClinic \\ Grosshansdorf, Grosshansdorf, \\ Germany; ${ }^{2}$ Pulmonary Research \\ Institute at LungenClinic \\ Grosshansdorf, Grosshansdorf, \\ Germany; ${ }^{3}$ Airway Research Center \\ North (ARCN), German Center for \\ Lung Research (DZL), Grosshansdorf, \\ Germany; ${ }^{4}$ Fraunhofer Institute \\ for Toxicology and Experimental \\ Medicine, Hannover, Germany; \\ ${ }^{5}$ Biomedical Research in Endstage and \\ Obstructive Lung Disease Hannover \\ (BREATH), German Center for \\ Lung Research (DZL), Hannover, \\ Germany; ${ }^{6}$ Department of Medicine, \\ Trelleborg Hospital, Trelleborg, \\ Sweden; ${ }^{7}$ Department of Respiratory \\ Medicine, Hannover Medical School, \\ Hannover, Germany
}

Introduction: Plasminogen activator inhibitor-1 (PAI-1), a major inhibitor of fibrinolysis, is associated with thrombosis, obesity, insulin resistance, dyslipidemia, and premature aging, which all are coexisting conditions of chronic obstructive pulmonary disease (COPD). The role of PAI-1 in COPD with respect to metabolic and cardiovascular functions is unclear.

Methods: In this study, which was nested within a prospective cohort study, the serum levels of PAI-1 were cross-sectionally measured in 74 stable COPD patients (Global Initiative for Chronic Obstructive Lung Disease [GOLD] Stages I-IV) and 18 controls without lung disease. In addition, triglycerides, high-density lipoprotein cholesterol, fasting plasma glucose, waist circumference, blood pressure, smoking status, high-sensitive C-reactive protein (hs-CRP), adiponectin, ankle-brachial index, N-terminal pro-B-type natriuretic peptide, and history of comorbidities were also determined.

Results: The serum levels of PAI-1 were significantly higher in COPD patients than in controls, independent of a broad spectrum of possible confounders including metabolic and cardiovascular dysfunction. A multivariate regression analysis revealed triglyceride and hs-CRP levels to be the best predictors of PAI-1 within COPD. GOLD Stages II and III remained independently associated with higher PAI-1 levels in a final regression analysis.

Conclusion: The data from the present study showed that the serum levels of PAI-1 are higher in patients with COPD and that moderate-to-severe airflow limitation, hypertriglyceridemia, and systemic inflammation are independent predictors of an elevated PAI-1 level. PAI-1 may be a potential biomarker candidate for COPD-specific and extra-pulmonary manifestations.

Keywords: plasminogen activator inhibitor-1, chronic obstructive pulmonary disease, cardiovascular disease, inflammation, hypertriglyceridemia, ankle-brachial index, N-terminal pro-B-type natriuretic peptide

\section{Introduction}

The coexistence of cardiovascular diseases (CVDs) and metabolic disorders is frequent in patients with chronic obstructive pulmonary disease (COPD). ${ }^{1}$ The prevalence of both these conditions is highest in patients with moderate-to-severe COPD in particular and drops in patients with very severe COPD. ${ }^{2}$ Accordingly, CVD is a leading cause of death in the earlier stage of the disease. ${ }^{3}$ Thrombosis, in turn, is the most frequent underlying mechanism of the three major CVDs: ischemic heart disease, stroke, and venous thromboembolism, ${ }^{4}$ which raises the question whether blood markers involved in the pathogenesis of thrombosis are linked to COPD.

Plasminogen activator inhibitor-1 (PAI-1) is a member of the superfamily of serine protease inhibitors and the principal inhibitor of fibrinolysis within the plasminogen
Correspondence: Benjamin Waschki LungenClinic Grosshansdorf,

Woehrendamm 80, 22927

Grosshansdorf, Germany

Email b.waschki@lungenclinic.de (c) (1) () 2017 Waschki et al. This work is published and licensed by Dove Medical Press Limited. The full terms of this license are available at https://www.dovepress.com/terms.php cc. ${ }_{\mathrm{BY}} \mathrm{NC}$ and incorporate the Creative Commons Attribution - Non Commercial (unported, v3.0) License (http://(creativecommons.org/licenses/by-n/ 3.00 ). By accessing the work you hereby accept the Terms. Non-commercial uses of the work are permitted without any further permission from Dove Medical Press Limited, provided the work is properly attributed. For permission for commercial use of this work, please see paragraphs 4.2 and 5 of our Terms (https://www.dovepress.com/terms.php). 
activator system. ${ }^{5,6}$ High concentration of PAI-1 plays a pivotal role in the pathogenesis of arterial and venous thrombosis and, therefore, precedes the occurrence of thrombotic events. ${ }^{7,8}$ In addition, higher level of PAI-1 is associated with obesity, insulin resistance, diabetes, hyperlipidemia, and premature aging. ${ }^{5,9,10}$ All these conditions are prevalent in COPD, ${ }^{11,12}$ and a potential influence of PAI-1 on an enhanced thrombogenesis in COPD has been hypothesized. ${ }^{13}$ Indeed, a recent case-control study demonstrated that PAI-1 polymorphisms related to a higher PAI-1 expression are associated with COPD. ${ }^{14}$ Furthermore, a study conducted on patients with predominantly mild-to-moderate COPD found that higher serum PAI-1 levels are related to airflow limitation. ${ }^{15}$ Whether the observed elevation in PAI-1 levels in COPD is independent of metabolic and cardiovascular functions is unknown.

In order to elucidate the clinical value of PAI-1 as a potential biomarker in COPD, the serum levels of PAI-1 and a broad spectrum of potential confounding factors for PAI-1 were analyzed in patients with mild-to-very severe COPD and in control subjects.

\section{Methods}

This cross-sectional study is nested within a prospective COPD cohort study conducted at the Pulmonary Research Institute, the LungenClinic Grosshansdorf(Grosshansdorf, Germany). Details regarding the COPD population and the methodology of the study have been published elsewhere. ${ }^{16-18}$ In the present study, 74 stable outpatients with mild-to-very severe COPD (ie, $\mathrm{n}=16,20,18$, and 20 with Global Initiative for Chronic Obstructive Lung Disease [GOLD] Stages I, II, III, and IV, respectively) and 18 nonsmoking controls without any lung disease from the 3-year follow-up visit were included. The study was approved by the Ethics Committee of the Medical Association of Schleswig-Holstein, Bad Segeberg, Germany (III/EK 116/05[I]; 185/08[I]), and all the participants provided written informed consent. In this study, the serum levels of PAI-1 were analyzed by using enzyme-linked immunosorbent assay (ELISA; Human Serpin E1/PAI-1 DuoSet ELISA; R\&D Systems, Wiesbaden-Nordenstadt, Germany; detection range $=0.312-20 \mathrm{ng} / \mathrm{mL})$; metabolic and cardiovascular functions as possible confounders of PAI-1, including triglyceride levels, high-density lipoprotein (HDL) cholesterol, fasting plasma glucose, waist circumference, blood pressure, the presence of the metabolic syndrome (based on the latter five variables according to the criteria of the International Diabetes Federation $^{19}$ ), smoking status, and history of coronary artery disease and diabetes, were determined; high-sensitivity C-reactive protein (hs-CRP) was measured as an established marker of systemic inflammation and adiponectin, which is involved in anti-inflammatory, anti-diabetic, and anti-atherogenic processes; ${ }^{20}$ in addition, global cardiac function by serum levels of N-terminal pro-B-type natriuretic peptide (NT-proBNP) and the presence of atherosclerosis by the ankle-brachial index (ABI) were also determined as previously described. ${ }^{16,18}$

First, the differences between groups were analyzed univariately by using unpaired $t$-test, $\chi^{2}$ test, and analysis of variance (ANOVA) with least significant difference post hoc analysis. Then, a multivariate linear regression analysis was conducted with PAI-1 as the dependent variable and COPD as a predictor, and adjustments for possible confounders, such as age, sex, body mass index (BMI), impaired fasting glucose (ie, $\geq 100 \mathrm{mg} / \mathrm{dL}$ ), ${ }^{19}$ dyslipidemia (ie, triglycerides $>150 \mathrm{mg} / \mathrm{dL}$ or $\mathrm{HDL}<40 \mathrm{mg} / \mathrm{dL}$ in male and $<50 \mathrm{mg} / \mathrm{dL}$ in female), ${ }^{19}$ cardiac dysfunction (ie, NTproBNP $>125 \mathrm{pg} / \mathrm{mL}$ ), ${ }^{21}$ atherosclerosis (ie, $\left.\mathrm{ABI} \leq 0.90\right),{ }^{22}$ as well as history of diabetes, hypertension, and coronary artery disease, were performed. A second multivariate regression analysis with PAI-1 as the dependent variable aimed at evaluating the best independent predictors for PAI-1 within COPD. Therefore, a stepwise approach was chosen with a backward elimination. Only the variables that showed at least a trend for statistical significance on the bivariate level, that is, $P<0.10$, were included in the model. Next, whether COPD severity stages were still independently associated with PAI-1 within the final model was proved. Last, the interaction effects of GOLD stages with the remaining predictors of the final model were tested by using separate two-way ANOVAs.

\section{Results}

Impaired fasting glucose, dyslipidemia, cardiac dysfunction, hypertension, and history of diabetes ( $P>0.05$, respectively; Table 1) did not differ between the patients with COPD and controls. The frequency of atherosclerosis and history of coronary artery disease increased in patients with COPD compared with controls $(P<0.05)$. Serum levels of PAI-1 were significantly higher in COPD patients than in controls (Figure 1A). Stratified by severity stages, PAI-1 levels were highest in GOLD Stages II and III (Figure 1B). Smoking status and statin use had no effect on the level of PAI-1 in patients with COPD ( $P=0.51$ and 0.50 , respectively). In a multivariate linear regression analysis, the presence of COPD remained an independent predictor for higher PAI-1 levels after adjustments for age, sex, BMI, impaired fasting glucose, dyslipidemia, cardiac dysfunction, hypertension, diabetes, atherosclerosis, and history of coronary artery disease (regression coefficient $B$ for COPD patients versus 
Table I Characteristics of patients with COPD and controls without any lung disease

\begin{tabular}{|c|c|c|c|}
\hline & Controls $(n=18)$ & COPD patients $(n=74)$ & $P$-value \\
\hline Age, years, mean (SD) & $65.9(5.8)$ & $66.0(6.6)$ & 0.99 \\
\hline Men, n (\%) & $11(6 I)$ & $52(70)$ & 0.45 \\
\hline Current smokers, n (\%) & $0(0)$ & $24(32)$ & 0.005 \\
\hline Pack-years of smoking, mean (SD) & $0.5(1)$ & $55(26)$ & $<0.001$ \\
\hline Body mass index, $\mathrm{kg} / \mathrm{m}^{2}$, mean (SD) & $25.7(4.6)$ & $26.0(5.3)$ & 0.82 \\
\hline FEV, \%pred, mean (SD) & $116.2(11.6)$ & $55.2(25.6)$ & $<0.001$ \\
\hline $\mathrm{FEV}_{1} / \mathrm{FVC}$, mean (SD) & $78.6(3.3)$ & $51.0(15.0)$ & $<0.001$ \\
\hline History of diabetes mellitus, $n(\%)$ & $0(0)$ & $7(10)$ & 0.18 \\
\hline Impaired fasting glucose, $\mathrm{n}(\%)$ & $4(22)$ & $32(43)$ & 0.10 \\
\hline Dyslipidemia, n (\%) & $6(33)$ & $19(26)$ & 0.35 \\
\hline Waist circumference, $>94 / 80 \mathrm{~cm}(\mathrm{M} / \mathrm{F}), \mathrm{n}(\%)$ & $11(6 I)$ & $59(80)$ & 0.10 \\
\hline Cardiac dysfunction, n (\%) & $3(17)$ & $27(37)$ & 0.11 \\
\hline Atherosclerosis, $\mathrm{n}(\%)$ & $0(0)$ & $21(29)$ & 0.009 \\
\hline History of coronary artery disease, n (\%) & $0(0)$ & $14(19)$ & 0.045 \\
\hline Hypertension, n (\%) & $12(67)$ & $57(77)$ & 0.36 \\
\hline hs-CRP, mg/L, median (IQR) & I.I $(0.6-2.0)$ & $3.0(1.5-6.1)$ & $<0.001$ \\
\hline Adiponectin, ng/mL, median (IQR) & $6,245(4,219-8,147)$ & $8,038(6,219-|1,65|)$ & 0.025 \\
\hline
\end{tabular}

Notes: Dyslipidemia = triglycerides $\geq 150 \mathrm{mg} / \mathrm{dL}$ or high-density lipoprotein $<40 \mathrm{mg} / \mathrm{dL}$ in men and $<50 \mathrm{mg} / \mathrm{dL}$ in women; impaired fasting glucose $=$ fasting plasma glucose $\geq 100 \mathrm{mg} / \mathrm{dL}$ or treatment; cardiac dysfunction $=\mathrm{NT}$-proBNP $>125 \mathrm{pg} / \mathrm{mL}$; atherosclerosis $=$ ankle-brachial index $\leq 0.90$. Differences of pack-years, FEV , and $\mathrm{FEV}_{1} / \mathrm{FVC}$ were tested by using rank test, as the homogeneity of variances was not given. hs-CRP and adiponectin were log-transformed to reveal a normal distribution. Abbreviations: COPD, chronic obstructive pulmonary disease; $\mathrm{FEV}_{1}$, forced expiratory volume in I s; FVC, forced vital capacity; hs-CRP, high-sensitive C-reactive protein; $\mathrm{IQR}$, interquartile range; M/F, male/female; NT-proBNP, N-terminal pro-B-type natriuretic peptide; SD, standard deviation.

controls $=2.9,95 \%$ confidence interval $[\mathrm{CI}]=0.34-5.41$, $P=0.027)$.

A next step was aimed at identifying the predictors for PAI-1 within COPD. Significant correlations of PAI-1 with HDL cholesterol, triglycerides, hs-CRP, and adiponectin $(P<0.05$, respectively; Table 2$)$ were found on the bivariate level. The association between age and PAI-1 showed a trend for significance $(P=0.058)$. In a multivariate regression analysis with a backward elimination, log-triglycerides (3.3, 95\% CI $=0.8-5.9, P=0.012)$ and log-hs-CRP $(0.83$,
95\% CI $=0.03-1.63, P=0.043)$ were found to be the best independent predictors for PAI-1 in COPD. Figure 2 visualizes the results from the multivariate regression analysis, that is, mean PAI-1 levels in COPD patients stratified according to triglycerides and hs-CRP in comparison with controls.

In a final model we studied whether COPD severity stages add additional information as predictors for PAI-1 independent of triglycerides and hs-CRP within the total study cohort. It was found that GOLD Stages II and III were independently associated with PAI-1 (Table 3). There were
A

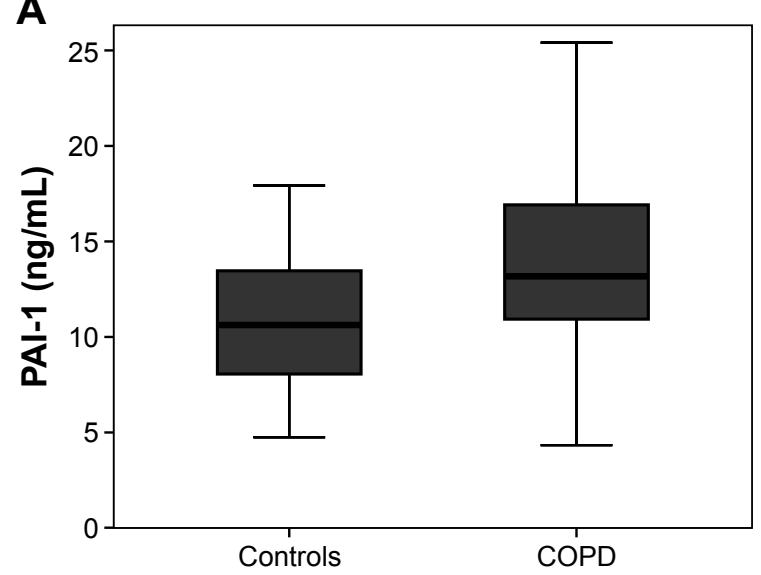

B

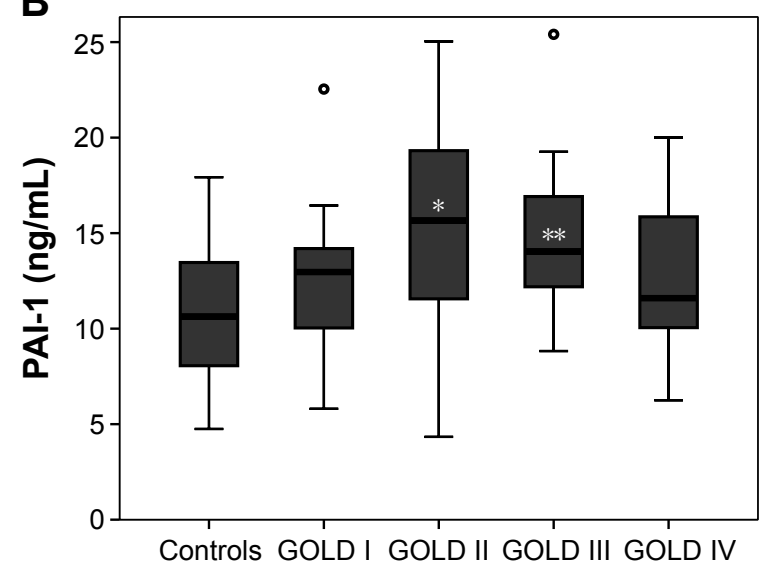

Figure I Serum levels of PAI-I (A) in patients with COPD and controls without any lung disease $(P=0.015)$ and (B) according to COPD severity.

Notes: After adjustment for a broad spectrum of possible confounders, PAI-I still differed significantly between COPD patients and controls $(P=0.027)$. After stratifying according to severity stages, PAI-I was highest in GOLD II followed by GOLD III ( $* P=0.003$ and $* * P=0.0$ I I for the comparison with controls). Lines represent the median, boxes represent the IQR, and circles represent outliers.

Abbreviations: COPD, chronic obstructive pulmonary disease; GOLD, Global Initiative for Chronic Obstructive Lung Disease; IQR, interquartile range; PAI- I, plasminogen activator inhibitor-I. 
Table 2 Bivariate associations of PAI-I with lung function, metabolic, cardiac, and inflammatory markers in patients with COPD

\begin{tabular}{lll}
\hline & $\boldsymbol{R}$ & $\boldsymbol{P}$-value \\
\hline Age, years & -0.22 & 0.058 \\
Body mass index, $\mathrm{kg} / \mathrm{m}^{2}$ & 0.01 & 0.93 \\
Waist circumference, cm & -0.01 & 0.96 \\
FEV, \%predicted & -0.07 & 0.55 \\
Log-triglycerides, $\mathrm{mg} / \mathrm{dL}$ & 0.31 & 0.007 \\
High-density lipoprotein cholesterol, mg/dL & -0.23 & 0.044 \\
Fasting plasma glucose, mg/dL & -0.16 & 0.19 \\
Ankle-brachial index & -0.02 & 0.36 \\
Log-NT-proBNP, pg/mL & 0.05 & 0.68 \\
Log-hs-CRP, mg/L & 0.25 & 0.035 \\
Log-adiponectin, ng/mL & -0.23 & 0.048 \\
\hline
\end{tabular}

Notes: Bivariate associations were analyzed by using Pearson correlations. NTproBNP, triglycerides, hs-CRP, and adiponectin were log-transformed to obtain a normal distribution.

Abbreviations: COPD, chronic obstructive pulmonary disease; $F E V_{1}$, forced expiratory volume in I s; hs-CRP, high-sensitive C-reactive protein; NT-proBNP, $\mathrm{N}$-terminal pro-B-type natriuretic peptide; PAI-I, plasminogen activator inhibitor-I.

no significant interaction effects of GOLD stages either on triglycerides or on hs-CRP.

\section{Discussion}

The main finding of the present study was that serum levels of PAI-1 are higher in patients with COPD independent of metabolic and cardiovascular disorders. Furthermore, hypertriglyceridemia and systemic inflammation were found to be the best independent predictors for higher PAI-1 levels in COPD patients, whereas the presence of moderate-to-severe airflow limitation remained to be independently associated with PAI-1.

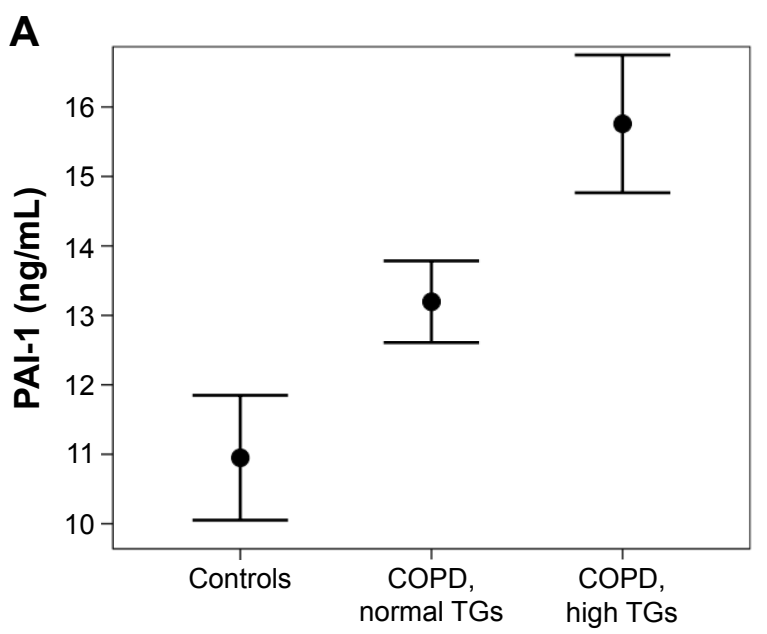

PAI-1 is a multifunctional protein associated with thrombosis as well as with metabolic conditions, such as obesity, dyslipidemia, insulin resistance, and diabetes, $5,7,9,10$ which all are important concomitant conditions of COPD. ${ }^{1,12}$ There are two very recent studies showing an association between elevated PAI-1 levels and COPD, but considered neither comorbidities of COPD nor the whole spectrum of airflow limitation, from mild to very severe stage. ${ }^{14,15}$ The present study is the first to demonstrate that higher serum PAI-1 levels in COPD are independent of a broad spectrum of possible confounders, in particular established variables indicating metabolic and cardiovascular dysfunction. Interestingly, this study found the highest PAI-1 levels in patients with GOLD Stages II and III. This observation is in good agreement with the finding of the previous study showing a significant association between higher levels of PAI-1 and airflow limitation in patients with predominantly mild-to-moderate COPD. ${ }^{15}$ Moreover, it was also found that triglycerides and hs-CRP are the best predictors for elevated PAI-1 levels in COPD patients. In general, an elevation in triglycerides and hs-CRP plays an important role for CVD. ${ }^{23,24}$ Moreover, an association of PAI-1 levels with serum lipids and inflammatory markers has been found, 9,25 although the mechanistic link behind this remains not fully understood. ${ }^{5,26}$ In patients with COPD, hypertriglyceridemia and systemic inflammation are also found frequently and predict mortality. ${ }^{27-29}$ The present study demonstrated an independent association of high PAI-1 serum levels with moderate-to-severe airflow limitation, hypertriglyceridemia, and systemic inflammation.

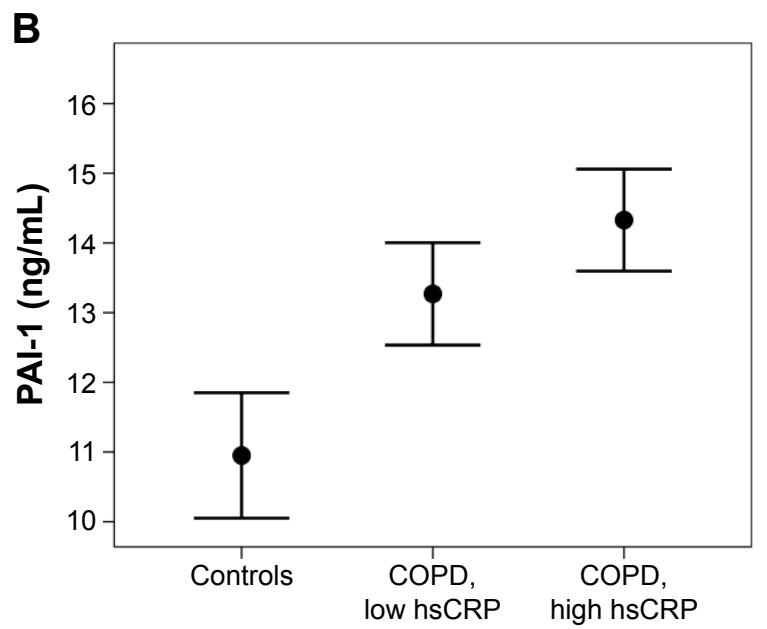

Figure 2 Mean serum PAI-I levels in controls and COPD patients according to (A) normal or elevated triglyceride levels (cutoff: I50 mg/dL) and (B) low or high hs-CRP (cutoff: median hs-CRP, ie, $3.0 \mathrm{mg} / \mathrm{L}$ ).

Notes: The control group also included five subjects (28\%) with elevated triglycerides and four subjects (22\%) with high hs-CRP levels. Points represent mean values and whiskers represent standard error.

Abbreviations: COPD, chronic obstructive pulmonary disease; hs-CRP, high-sensitive C-reactive protein; PAI-I, plasminogen activator inhibitor-I; TGs, triglycerides. 
Table 3 Independent predictors for the level of PAI-I - a multivariate linear regression analysis

\begin{tabular}{|c|c|c|c|}
\hline & $\begin{array}{l}\text { Coefficient B } \\
(95 \% \mathrm{Cl})\end{array}$ & $\begin{array}{l}\text { Standardized } \\
\beta\end{array}$ & $P$-value \\
\hline Age, years & $-0.10(-0.24$ to 0.04$)$ & -0.14 & 0.14 \\
\hline Sex, male & $0.14(-1.75$ to 2.03$)$ & 0.02 & 0.88 \\
\hline $\begin{array}{l}\text { Log-triglycerides, } \\
\mathrm{mg} / \mathrm{dL}\end{array}$ & $2.46(0.22$ to 4.70$)$ & 0.22 & 0.032 \\
\hline Log-hs-CRP, mg/L & $0.82(0.06$ to I.58) & 0.23 & 0.034 \\
\hline GOLD Stage I & $0.99(-1.84$ to 3.82$)$ & 0.08 & 0.49 \\
\hline GOLD Stage II & $3.02(0.28$ to 5.75$)$ & 0.28 & 0.031 \\
\hline GOLD Stage III & 2.81 (0.02 to 5.59$)$ & 0.25 & 0.048 \\
\hline GOLD Stage IV & $0.70(-2.19$ to 3.60$)$ & 0.07 & 0.63 \\
\hline
\end{tabular}

Notes: Data from the multivariate linear regression analysis for the total study cohort $(n=92)$ with PAI-I as the dependent variable are shown. First, age and sex were included in the model, followed by both independent predictors for PAI-I derived from the former model within COPD patients, that is, triglycerides and hs-CRP. Last, GOLD stages were included in the model after they were dummycoded with controls as the reference category. Triglycerides and hs-CRP were logtransformed to obtain a normal distribution.

Abbreviations: COPD, chronic obstructive pulmonary disease; GOLD, Global Initiative for Chronic Obstructive Lung Disease; hs-CRP, high-sensitive C-reactive protein; PAI-I, plasminogen activator inhibitor-I.

COPD is characterized by airway and lung abnormalities and is frequently complicated by concomitant cardiovascular and metabolic disorders. ${ }^{1}$ Local pathological changes of COPD include parenchymal tissue destruction, resulting in emphysema, and disrupted repair and defense mechanisms, resulting in small airway fibrosis. ${ }^{1}$ PAI-1 is synthesized by a variety of cells including vascular endothelial cells, macrophages, and fibroblasts and not only is involved in the pathogenesis of thrombosis but also activates tissue repair. ${ }^{30-32}$ Transiently increased levels of PAI-1 may protect extracellular matrix proteins from proteolytic degradation, inducing matrix remodeling and enhancing wound healing. ${ }^{33,34}$ It is well documented that tissue homeostasis is maintained by the balance of extracellular matrix synthesis and degradation depending on the cellular proteolytic activities of urokinase-type/tissue-type plasminogen activator and plasmin, which mostly rely on the activity of PAI-1. ${ }^{33,35}$ According to the data from the present study, the independent elevation of PAI-1 in patients with COPD may indicate a disease-specific mechanism. We speculate that higher PAI-1 levels may to some extent reflect processes of airway remodeling in COPD. These processes start early in the course of the disease and are less present in advanced COPD ${ }^{36}$ which might be the reason why the PAI-1 level is highest in moderate COPD. This concept is in good agreement with the findings of Hogg et al showing that indicators of small airway remodeling are increased in moderate COPD in comparison with controls and declined in very severe COPD again. ${ }^{36}$ In line with this result, the plasminogen activator system has already been identified as a potential treatment target for chronic respiratory diseases including COPD. ${ }^{37}$

On the other hand, the pivotal role of PAI-1 in the pathogenesis of thrombosis, in general, seems to be clear, ${ }^{5,7-10}$ which allows to propose that higher levels of PAI-1 in patients with moderate-to-severe COPD (GOLD Stages II and III) may be associated with an increased risk for cardiovascular events. This idea is supported by the observation that CVD and cardiovascular mortality are highest in patients with moderate-to-severe COPD and drops in very severe COPD. ${ }^{2,3}$ Overall, PAI-1 is recognized as one of the central molecules linking the metabolic syndrome/obesity to the increased CVD risk. ${ }^{26,38}$ Beyond its function as a tissue-remodeling activator, PAI-1 is also an adipocytokine, which is upregulated along with fat accumulation and, therefore, is associated with insulin resistance, dyslipidemia, and obesity. ${ }^{5,9,26,38}$ Metabolic comorbidities are, in turn, especially prevalent in COPD patients with GOLD Stages II and III. ${ }^{2}$ Altogether, PAI-1 may serve as a cross-talk molecule between airway remodeling during the course of COPD, accompanied metabolic comorbidities, and a subsequent increased risk for cardiovascular events, especially in moderate COPD.

The present study has some limitations. First, this is a cross-sectional study and therefore does not allow any interpretation on causality. The elevation of PAI-1 in COPD could also represent a bystander effect. However, it was indicated that PAI-1 may play a plausible role in COPD, and this is the first study conducted in a well-characterized COPD cohort to demonstrate a clear association of PAI-1 with COPD independent of a broad range of possible confounders. Second, the sample size, especially in the control group, is small. Despite these limitations, a significant difference in PAI-1 between COPD patients and controls was found. Of note, the control subjects were free from lung diseases but not explicitly healthy and, therefore, were well matched in terms of metabolic comorbidities. Furthermore, for remaining differences in some cardiovascular conditions, statistical adjustments were performed. Nevertheless, further studies are needed to confirm these observations and to evaluate the role of PAI-1 for cardiovascular outcomes in COPD.

\section{Conclusion}

The results of this study showed that PAI-1 levels are higher in patients with COPD, independent of metabolic disorders and cardiovascular function. Hypertriglyceridemia and systemic inflammation may play a role for elevated levels of PAI-1 in COPD, even though they do 
not explain this elevation solely, as moderate-to-severe airflow limitation is independently associated with higher levels of PAI-1. These findings suggest PAI-1 as a potential biomarker candidate that indicates a link between airway remodeling, metabolic comorbidities, and an increased cardiovascular risk.

\section{Acknowledgment}

This study was supported by the German Center for Lung Research (Deutsches Zentrum für Lungenforschung [DZL]) and Sir Bo Hjelt.

\section{Disclosure}

The authors report no conflicts of interest in this work.

\section{References}

1. Vestbo J, Hurd SS, Agusti AG, et al. Global strategy for the diagnosis, management, and prevention of chronic obstructive pulmonary disease: GOLD executive summary. Am J Respir Crit Care Med. 2013; 187:347-365.

2. Dal Negro RW, Bonadiman L, Turco P. Prevalence of different comorbidities in COPD patients by gender and GOLD stage. Multidiscip Respir Med. 2015;10:24.

3. Sin DD, Anthonisen NR, Soriano JB, Agusti AG. Mortality in COPD: role of comorbidities. Eur Respir J. 2006;28:1245-1257.

4. ISTH Steering Committee for World Thrombosis Day. Thrombosis: a major contributor to global disease burden. Thromb Res. 2014;134: 931-938.

5. Cesari M, Pahor M, Incalzi RA. Plasminogen activator inhibitor-1 (PAI-1): a key factor linking fibrinolysis and age-related subclinical and clinical conditions. Cardiovasc Ther. 2010;28:e72-e91.

6. Loskutoff DJ, Sawdey M, Mimuro J. Type 1 plasminogen activator inhibitor. Prog Hemost Thromb. 1989;9:87-115.

7. Sobel BE. Increased plasminogen activator inhibitor-1 and vasculopathy. A reconcilable paradox. Circulation. 1999;99:2496-2498.

8. Juhan-Vague I, Pyke SD, Alessi MC, Jespersen J, Haverkate F, Thompson SG. Fibrinolytic factors and the risk of myocardial infarction or sudden death in patients with angina pectoris. ECAT Study Group. European Concerted Action on Thrombosis and Disabilities. Circulation. 1996;94:2057-2063.

9. Juhan-Vague I, Alessi MC, Mavri A, Morange PE. Plasminogen activator inhibitor-1, inflammation, obesity, insulin resistance and vascular risk. J Thromb Haemost. 2003;1:1575-1579.

10. Yamamoto K, Takeshita K, Kojima T, Takamatsu J, Saito H. Aging and plasminogen activator inhibitor-1 (PAI-1) regulation: implication in the pathogenesis of thrombotic disorders in the elderly. Cardiovasc Res. 2005;66:276-285.

11. Cavailles A, Brinchault-Rabin G, Dixmier A, et al. Comorbidities of COPD. Eur Respir Rev. 2013;22:454-475.

12. Ito K, Barnes PJ. COPD as a disease of accelerated lung aging. Chest. 2009;135:173-180.

13. Tapson VF. The role of smoking in coagulation and thromboembolism in chronic obstructive pulmonary disease. Proc Am Thorac Soc. 2005;2: $71-77$.

14. Essa ES, El Wahsh RA. Association between plasminogen activator inhibitor-1-675 4G/5G insertion/deletion polymorphism and chronic obstructive pulmonary disease. COPD. 2016;13:756-759.

15. Wang H, Yang T, Li D, et al. Elevated circulating PAI-1 levels are related to lung function decline, systemic inflammation, and small airway obstruction in chronic obstructive pulmonary disease. Int $J$ Chron Obstruct Pulmon Dis. 2016;11:2369-2376.
16. Watz H, Waschki B, Boehme C, Claussen M, Meyer T, Magnussen H. Extrapulmonary effects of chronic obstructive pulmonary disease on physical activity: a cross-sectional study. Am J Respir Crit Care Med. 2008; 177:743-751.

17. Waschki B, Kirsten AM, Holz O, et al. Disease progression and changes in physical activity in patients with chronic obstructive pulmonary disease. Am J Respir Crit Care Med. 2015;192:295-306.

18. Waschki B, Kirsten A, Holz O, et al. Angiopoietin-like protein 4 and cardiovascular function in COPD. BMJ Open Respir Res. 2016;3: e000161.

19. Alberti KG, Zimmet P, Shaw J. The metabolic syndrome-a new worldwide definition. Lancet. 2005;366:1059-1062.

20. Wouters EF. Adiponectin: a novel link between adipose tissue and chronic obstructive pulmonary disease. Am J Respir Crit Care Med. 2013;188:522-523.

21. McMurray JJ, Adamopoulos S, Anker SD, et al. ESC guidelines for the diagnosis and treatment of acute and chronic heart failure 2012: The Task Force for the Diagnosis and Treatment of Acute and Chronic Heart Failure 2012 of the European Society of Cardiology. Developed in collaboration with the Heart Failure Association (HFA) of the ESC. Eur J Heart Fail. 2012;14:803-869.

22. Aboyans V, Criqui MH, Abraham P, et al. Measurement and interpretation of the ankle-brachial index: a scientific statement from the American Heart Association. Circulation. 2012;126:2890-2909.

23. Libby P. Triglycerides on the rise: should we swap seats on the seesaw? Eur Heart J. 2015;36:774-776.

24. Strang F, Schunkert H. C-reactive protein and coronary heart disease: all said-is not it? Mediators Inflamm. 2014;2014:757123.

25. Crutchley DJ, McPhee GV, Terris MF, Canossa-Terris MA. Levels of three hemostatic factors in relation to serum lipids. Monocyte procoagulant activity, tissue plasminogen activator, and type-1 plasminogen activator inhibitor. Arteriosclerosis. 1989;9:934-939.

26. Alessi MC, Juhan-Vague I. PAI-1 and the metabolic syndrome: links, causes, and consequences. Arterioscler Thromb Vasc Biol. 2006;26: 2200-2207.

27. Dahl M, Vestbo J, Lange P, Bojesen SE, Tybjaerg-Hansen A, Nordestgaard BG. C-reactive protein as a predictor of prognosis in chronic obstructive pulmonary disease. Am J Respir Crit Care Med. 2007; 175:250-255.

28. Fabbri LM, Rabe KF. From COPD to chronic systemic inflammatory syndrome? Lancet. 2007;370:797-799.

29. Tanni SE, Zamuner AT, Coelho LS, Vale SA, Godoy I, Paiva SA. Are metabolic syndrome and its components associated with 5-year mortality in chronic obstructive pulmonary disease patients? Metab Syndr Relat Disord. 2015;13:52-54.

30. Idell S. Coagulation, fibrinolysis, and fibrin deposition in acute lung injury. Crit Care Med. 2003;31:S213-S220.

31. Kucharewicz I, Kowal K, Buczko W, Bodzenta-Lukaszyk A. The plasmin system in airway remodeling. Thromb Res. 2003;112:1-7.

32. Park JA, Fredberg JJ, Drazen JM. Putting the squeeze on airway epithelia. Physiology (Bethesda). 2015;30:293-303.

33. Ghosh AK, Vaughan DE. PAI-1 in tissue fibrosis. J Cellular Physiol. 2012;227:493-507.

34. Vassalli JD, Sappino AP, Belin D. The plasminogen activator/plasmin system. J Clin Invest. 1991;88:1067-1072.

35. Visse R, Nagase H. Matrix metalloproteinases and tissue inhibitors of metalloproteinases: structure, function, and biochemistry. Circ Res. 2003; 92:827-839.

36. Hogg JC, McDonough JE, Gosselink JV, Hayashi S. What drives the peripheral lung-remodeling process in chronic obstructive pulmonary disease? Proc Am Thorac Soc. 2009;6:668-672.

37. Schuliga M, Westall G, Xia Y, Stewart AG. The plasminogen activation system: new targets in lung inflammation and remodeling. Curr Opin Pharmacol. 2013;13:386-393.

38. Barnard SA, Pieters M, De Lange Z. The contribution of different adipose tissue depots to plasma plasminogen activator inhibitor-1 (PAI-1) levels. Blood Rev. 2016;30:421-429. 
International Journal of COPD

\section{Publish your work in this journal}

The International Journal of COPD is an international, peer-reviewed journal of therapeutics and pharmacology focusing on concise rapid reporting of clinical studies and reviews in COPD. Special focus is given to the pathophysiological processes underlying the disease, intervention programs, patient focused education, and self management protocols.

This journal is indexed on PubMed Central, MedLine and CAS. The manuscript management system is completely online and includes a very quick and fair peer-review system, which is all easy to use. Visit http://www.dovepress.com/testimonials.php to read real quotes from published authors 